International Research Journal of Obstetrics and Gynecology
(ISSN:2639-6009)

\title{
Nursing Care for Women With Postpartum Blues: A Literature Review
}

\section{Kimberly Mayara Gouveia Bezerra1*; Ana Carolina de Carvalho Leandro²; Cayo César da Silva ${ }^{3}$; Scarlletie Rodrigues Perreli Batista de Oliveira ${ }^{4}$ Thassia Thame de Moura Silva ${ }^{5}$; Iracema da Silva Frazão ${ }^{6}$}

\section{${ }^{1,2,3,4}$ Nursing Academics - UFPE; 5,6 Professors of the Nursing Department - UFPE}

\section{ABSTRACT}

Introduction: During the puerperal period the woman becomes more sensitive, requiring more emotional support, attention and affection, as it becomes more susceptible to hormonal, psychological and social changes due to the need to adjust to the new role, that of being a mother, which can lead to internal and external conflicts that can directly influence your mental health. Thus, nursing care for puerperal women is of fundamental importance so that they can understand the emotions and changes experienced in this phase, as well as for the identification and monitoring of these cases. Objective: To analyze what the current literature evidences about nursing care for women with puerperal Blues. Methodology: Literature review in MEDLINE, BDENF, LILACS and PubMed databases. A total of 96 articles were found, of which 23 were pre - selected and after the inclusion criteria were applied, 16 remained. A reading of these in full with peer review was performed, and they were subsequently crossed to discuss the divergences found in order to reduce interpretation errors. Results: According to the literature, about $50 \%$ of women present puerperal Blues in up to two weeks postpartum, that if there is no necessary therapy, more than $20 \%$ of these women tend to develop postpartum depression (PPD). Conclusion: Therefore, an appropriate approach and performed by trained professionals is paramount to identify the factors associated with puerperal blues during puerperium consultations, so that there is the ideal management to promote a better Quality of life, avoiding mental distress.

Keywords: Nursing, Postpartum Period, Delivery of Health Care, Postpartum blues
*Correspondence to Author: Kimberly Mayara Gouveia Bezerra Nursing Academics - UFPE

How to cite this article:

Kimberly Mayara Gouveia Bezerra; Ana Carolina de Carvalho Leandro; Cayo César da Silva; Scarlletie Rodrigues Perreli Batista de Oliveira; Thassia Thame de Moura Silva; Iracema da Silva Frazão. Nursing Care for Women With Postpartum Blues: A Literature Review. International Research Journal of Obstetrics and Gynecology, 2020, 3:24

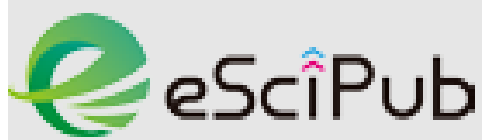
eSciPub LLC, Houston, TX USA. Website: https://escipub.com/ 


\section{INTRODUCTION}

During the postpartum the woman stay be more a sensitive, demanding more emotional support, attention and affection, because she becomes to more susceptible the hormonal, psychological and social alterations due to need of adjustment to the new paper, to have children, that it can foster internal and external conflicts, that can directly influence your mental health. In addition, the postpartum also involves an identification process and creation a link between the mother and your baby, that moment is permeated by changes, don't just only of to this binomial, more too for all social circle of the relationships ${ }^{1}, 2$. The postpartum blues, is also known as the dystrophy and sadness puerperal, Maternity Blues or Postpartum Blues is classified in CID-10 in the subgroup F53, characterized by labile humor, excessive sensitivity, crying without reason, anxiety and irritability. It tends to appear in the first 10 days postpartum, with a peak between 3 and 5 days. There is still no consensus regarding the possibility or not of depressed humor, and there is little conformity in its definition and description, but it is considered as a disturbance of humor $^{2,3}$. A high number of women experience puerperal Blues in the first week after the Childbirth, but when it persists for more than two weeks it can make them vulnerable to severe forms of mood disorder. Even with this high epidemiological quantitative, there are few studies on the subject, and there is a more sharp look only to postpartum depression ${ }^{4}$. This fact can be explained by the diagnostic difficulty and the lack of scientific methods for this Exploration. Early screening and diagnosis are very important, requiring training of health professionals to regularly examine mothers during visits and postpartum consultations ${ }^{5,6}$. Therefore, nursing care in the puerperal period is of fundamental importance for understanding the emotions and changes experienced in this phase and in the identification and follow-up of these cases, in order to promote a qualified and humanized care for the purpose of promoting quality of life and health recovery, since the puerperal woman should have access to qualified care, in which it is possible to share the anxieties and clarify doubts to maturation and answers the novelties of the puerperium.

\section{OBJECTIVE}

To analyze the current literature evidence about nursing care for women with puerperal Blues.

\section{METHODOLOGY}

A search was conducted in the literature in the Databases MEDLINE, BDENF (Database of Nursing), LILACS (Latin American and Caribbean Literature in Health Sciences) and PubMed, with the association of the descriptors in Portuguese "Enfermagem", "Período pós-parto", "Blues puerperal" and "Saúde Mental" and the corresponding English descriptors "Nursing", "Postpartum Period", "Postpartum Blues" and "Mental Health" respectively, using inclusion criteria (full article available, English and Portuguese language, with the last 5 years (2015-2019). After the search in the bases, 96 articles were found in total, of which 23 were preselected after reading the titles and abstracts to verify the relevance and coherence with the theme studied. Subsequently, a complete reading of these pre-selected articles was performed, with 16 studies remaining, which comprised the abstract. The studies were read with peer evaluation and subsequently crossed to discuss the divergences found to reduce interpretation errors.

\section{RESULTS}


The Puerperal blues represents a transient emotional disorder, whose symptoms start in the first days after delivery, reach their peak around the fifth day and relive spontaneously in up to two weeks. The literature shows that on average $50 \%$ $(15.3 \%$ to $85 \%)$ of women experience puerperal Blues in the first week after childbirth $^{6,7}$. Without receiving adequate assistance with guidelines to deal with their condition, more than $20 \%$ of these women can develop postpartum depression (PPD), which requires rapid, specific and effective treatment ${ }^{8} \cdot$ Moreover, studies show that the development of puerperal Blues represents an important factor for early weaning, which makes it a public health problem since breastfeeding significantly decreases neonatal mortality ${ }^{9,10}$.

Among the factors associated with puerperal Blues are the relationship of low quality with the partner, because it can negatively affect the emotional condition of the mother, as well as the lack of social support, the low level of self-realization, the perception of lack of support and Specific instructions in the puerperal period to care for the newborn and to deal with emotional issues and the low quality of sleep predispose the development of this condition. Another factor evidenced in the literature is the neuroticism, a trait of personality associated with the risk of postpartum sadness, which makes the woman little adaptable and emotionally unstable and shows a generalized tendency to feel negative emotions ${ }^{11}$. During the home visits and post-natal consultations performed by the nurse is essential to evaluate the status of the relationship, social support, sleep quality and personality traits in postpartum women to detect possible mental disorders ${ }^{12,13}$.

As main guidelines to minimize the event and its associated factors, it is noteworthy to improve the coverage of pre-and post-natal consultations, to empower nursing professionals for a better approach and counseling through active listening and Qualified, promote multidisciplinary collaboration, include emotional and psychological aspects in the consultation sheets, strengthen the support of the Family network and develop devices capable of providing subsidies to potentialize the ways of living of Women in the puerperal period ${ }^{14}$, 15. In addition to the above, the nurse can also investigate the previous history and antecedents in mental health, observe the social bonds and verbal and non-verbal communications, as well as perform support groups with pregnant and puerperal women, as it represents a figure Fundamental in the care and support of women in the face of changes and novelties that happen in this phase $^{15}$.

Therefore, as an educator, the nurse needs to allow a moment of speech and openness to these women, such as providing emotional support, conducting guidance regarding their Self-care and care for the newborn, besides promoting empowerment and elaboration of strategies for women to cope with their emotional difficulties, because nursing has an important role in the implementation of humanization either in the care directly to users or in the management of health services. However, it is perceived that most of the time, nursing care is limited to orientations regarding care for the newborn and a lower concern lies under the aspects of women's health control, with the dedication to the puerperal woman who is very fragile, Almost nil. Therefore, the woman ends up being in need, on her account, to ask for information and support, and this should have been offered before the lack of care ${ }^{16}$. Therefore, it appears that although the majority of women in the 
postpartum period manifest the puerperal blues, the care provided is still neglected because there is no awareness on the part of professionals about their real importance, since most Of the studies found focus on postpartum depression and do not emphasize the indispensable of having a look towards women with puerperal Blues.

\section{CONCLUSION}

An adequate approach is essential to contemplate the aspects of care integrality related to nursing care to women in the postpartum period and represents the possibility of preventing the occurrence of mental disorders and Behavioral. Therefore, we highlight the need for training professionals, improvements in working conditions, inclusion of care actions aimed at all aspects of women, besides an update on the factors that are considered essential by the literature. During consultations and puerperium visits, the nurse may, through active and qualified listening, analyze postpartum women who present the puerperal blues so that there is correct management of the situation and the promotion of their quality of life, avoiding the suffering Psychic. It is acknowledged that the analysis of the studies found is considered valid for the initiation of discussions about nursing care to puerperal Blues, and that the study cut does not represent the totality of the researches developed. Therefore, further studies are needed to emphasize the importance of the theme in question to confer visibility to the need for the clinical approach and the promotion of improvements for nursing care to women's health in the postpartum period.

\section{REFERENCES}

1. Maciel LP, Costa JCC, Campor GMB, Santos NM, Melo RA, Diniz LFB. Mental disorder in the puerperal period: risks and coping mechanisms for health promotion. Rev Fun Care Online. 2019 jul/set; 11(4):1096-1102.
DOI: $\quad$ http://dx.doi.org/10.9789/21755361.2019.v11i4.1096-1102.

2. Silva MAP, et al. Tristeza Materna em Puérperas e Fatores Associados. Revista Portuguesa de Enfermagem de Saúde Mental (18) 2018, 08-13. doi: 10.19131/rpesm.0186

3. Pereira MA, Pelloso SM. Epidemiologia da tristeza em puérperas no pós-parto imediato. Femina, 2015 v. 35, n. 6.

4. Espinoza $M$, et al. Tristeza no puerpério. Rev.Obstet.Ginecol. 2015; VOL 10 (2): 65-72

5. Maliszewska K, et al. Relationship, social support, and personality as psychosocial determinants of the risk for postpartum blues. Ginekologia Polska 2016; 87, 6: 442447. DOI: $10.5603 / G P .2016 .0023$

6. Carvalho GM, et al. Transtornos mentais em puérperas: análise da produção de conhecimento nos últimos anos. Braz. J. Hea. Rev., Curitiba, v. 2, n. 4, p. 3541-3558 jul./aug. 2019 DOI:10.34119/bjhrv2n4-117

7. Dowlatia $Y$, et al. Selective dietary supplementation in early postpartum is associated with high resilience against depressed mood. PNAS, March 28, 2017 vol. 114 no. 13, p 3509-3514.

8. Thitipitchayanant K, Somrongthong R, Kumar R, Kanchanakharn N. Effectiveness of self-empowerment-affirmation-relaxation

(SelfEAR) program for postpartum blues mothers: A randomize controlled trial. Pak J Med Sci. 2018;34(6):1488-1493. DOI: https://doi.org/10.12669/pjms.346.15986

9. Kumar SV, Oliffe JL, Kelly MT. Promoting Postpartum Mental Health in Fathers: Recommendations for Nurse Practitioners. American Journal of Men's Health 2018, Vol. 12(2) $221-228$

10. Tachibana y, et al. Integrated mental health care in a multidisciplinary maternal and child health service in the community: the findings from the Suzaka trial.. BMC Pregnancy and Childbirth 2019, 19:58. DOI: https://doi.org/10.1186/s12884-019-2179-9

11. Rai S, Pathak S, Sharma I. Postpartum psychiatric disorders: Early diagnosis and management. Indian J Psychiatry 57 (Supplement 2), July 2015. DOI: 10.4103/0019-5545.161481

12. Berger A, et al. Perinatal mental disorders in Switzerland: prevalence estimates and use of mental-health services. Swiss Med Wkly. 2017;147:w14417. 10.4414/smw.2017.14417 
13. Akbarzadeh $M$, et al. Investigation of the effect of religious doctrines on religious knowledge and attitude and postpartum blues in primiparous women. Iranian Journal of Nursing and Midwifery Research | September-October 2015, Vol. 20, Issue 21(3): 636-647. DOI:10.1007/s10995-0162150-6.

14. Maciel LP et al. Mental disorder in the puerperal period: risks and coping mechanisms for health promotion. Rev Fun Care Online. 2019 jul/set; 11(4):1096-1102. DOI: $\quad$ http://dx.doi.org/10.9789/21755361.2019.v11i4.1096-1102.

15. Akbarzadeh $M$, et al. Investigation of breastfeeding training based on BASNEF model on the intensity of postpartum blues. EMHJ, Vol. 23 No. 12, 2017. DOI: https://doi.org/10.26719/2017.23.12.830

16. Wouk K, Stuebe AM, Meltzer-Brody S. Postpartum Mental Health and Breastfeeding Practices: An Analysis Using the 2010-2011 Pregnancy Risk Assessment Monitoring System. Matern Child Health J . 2017 March:5 